\title{
ABSTRACTS
}

\section{A STUDY ON THE HUMAN RELATIONSHIP BETWEEN PUPIL AND TEACHER : II}

-With Special Emphasis on the Effects of Teachers'

Conditions upon the Pupils' Attitude toward them-

by

Kishida, Motomi

Tokushimá University

This study is the 2nd report by the author concerning the study on the human relationship between pupil and teacher. The 1st report was an analysis of pupils' attitude toward their teachers. In order to confirm the points which had been proposed in the 1st report, the author took six teachers as subjects and investigated their personality traits and the educational attitude toward their pupils which had caused the differences in the pupils' attitude toward them.

As personality traits, sex, age, intro-extro vert, the term of teaching experience and final schooling were adopted. In order to investigate the patterns of teachers' educational attitude toword the pupils, a questionnaire was made, asking the teachers their daily attitude toward the pupils. The questionnaire consisted of five investigation sheets ; (1) affectionate.......indifferent (2) authoritative......laissez-faire (3) strict......liberal (4) devoted......neglectful (5) qualified......unqualified.

The pupils' attitude toward their teaehers was then compared with the teachers' personality traits and educational attitude toward the pupils.

The main results of the investigation were as follow; The teachers' sex and age scarecely influenced upon the pupils' attitude toward them but their educational attitude toward the pupils much influenced upon it. Those teachers who had more desirable human relations to their pupils were identified as qualified, devoted, liberal and affectionate.

\section{ON CONSCIENCE OF JAPANESE JUNIOR HIGH SCHOOL STUDENTS}

\author{
-Their Moral Awakening-
}

by

Imamura, Ken-ichiro

Pre-adolescent agers are said to be in the age that they realize what fairness is and what is not. They will hardly be indoctorinated by the so-called pseu- do-equalism in the present transitory world, but will tend toward the age of "fairness" profoundly generated in the spirit of mutual respect. 